\title{
Into the Mind of Terrorist \& Violent-Extremist: A Neuroscience Perspective \& Review on Radicalization
}

\author{
Sabiqotul Husna* \\ Psychology Department, \\ Faculty of Social \& Humanity Sciences \\ UIN Sunan Kalijaga \\ D.I.Yogyakarta, Indonesia \\ sabiqotul.husna@uin-suka.ac.id
}

\begin{abstract}
Neuroscience studies are currently drawing the baseline on neurobiological mechanism behind the mind of terrorist and violent-extremist through several interdisciplinary research. As the current state of terrorism and radicalization has been continuously studied in diverse fields such as Sociology, Political Science, Criminology, Conflict Resolution, Economic Science, Social Psychology, Clinical Psychology and more, yet it seems there is just few approaches has been implemented to understand the complexities of terrorism and radicalization through bottomup neurobiological analyses. This paper aims to provide comprehensive review of neuroscience research and approach on terrorism and radicalism through interdisciplinary studies. The database used for this literature review includes several international journal databases related to neuroscience, neurobiology, radicalization, terrorism, extremism, criminal psychology, and social neuroscience. From the mentioned journal database, it has been concluded that the integrative multi-layer approaches which included neuroscience perspective have giving more comprehensive empirical clarity on socio-genic level as well as new fruitful insights on neural basis and neurobiology mechanism which explained the mind of terrorist and violent-extremist, particularly on the contributions of genetic predictors, justice sensitivity, cognitive flexibility, neural basis and cognitive closure within radicalization process. More future multi-layer perspectivebased studies are on demand to interpret and explore comprehensively the gene-culture reciprocal interaction on the radicalism and terrorism complexities
\end{abstract}

Keywords-neuroscience, social neuroscience, terrorism, violent-extremism, radicalization, neurobiology, cognitive process

\section{INTRODUCTION}

Radicalization, terrorism and extremism have been analyzed and studied by many researchers and scholars from diverse disciplines, ranging from the sociology perspective, political science analyses, criminological point of view, conflict resolution approach, economic science analyses, social psychology viewpoint to clinical psychology context. However, several meta-analyses and reviews on those mentioned disciplines and fields draw a conclusion that those areas should be more integrated with other new disciplines. One area that has been suggested by many researchers was neuroscience which tends to be seen as one of biological approaches.

To begin with, previous scholars and researchers proposed the explanation for terrorists' behavior only focus on social organization characteristic belongs to those people who executed terror acts, our scientists does not analyze its antecedents in psychopathological traits [1]

Decety \& Workman [2] highlighted the importance of integrative and multilevel studied that put neuroscience as a new potential approach to understand the radicalization and terrorism antecedents. Accordingly, Saadat [3] also discussed the need of integrative approach using top-down and bottomup perspective to investigate comprehensively the radicalization process. As previous studies were executed using more top-down approaches and generally focused on the model development of sociogenic and psychogenic perspective, as found in criminology, sociology, political psychology and social psychology.

The lack of bottom-up component has been mentioned as well by several scientists on their papers and articles that will be discussed in this literature review. As Victoroff [4] stated, one factor of the drawbacks for top-down approach is the study into radicalization, extremism and terrorism basically only focused on social, political, and economic components. They left the bottom-up viewpoint which could be the missing piece for understanding the issue precisely through individual disposition and brain-behavior-based theories. Furthermore, Decety \& Workman [2] also concluded various fields included political science, social psychology, criminology and so on failed to produce comprehensive working model for the explanation behind extremist mind.

Earlier, Cacioppo \& Decety [5] explained it is very important as well to leave the single-dimensional approach and to move on to the interdisciplinary approach. One of the proposed interdisciplinary approaches is the social neuroscience. As an umbrella discipline, the social neuroscience has high articulation of inquiry which covers multiple fields including psychology, economics, sociology, and biology in terms of elaborating social cognition and behavior.

The goal of this literature review is to discussed and to elaborated the neuroscience related research on individual disposition and cognitive-biological analyses underlying the mechanism of radicalization, terrorism and extremism. Prior to this proposed goal, this review will not explore the politic, sociology and economic related perspectives in detail that use single dimensional-analyses. 


\section{INDIVIDUAL DISPOSITION; JUSTICE SENSITIVITY}

Carson, Lafree \& Dugan [6] described terrorism as 'the threatened or actual use of illegal force and violence to attain a political, economic, religious or social goal through fear, coercion or intimidation'. Meanwhile Koomen \& Pligt (in Sadat) [3] gave elaboration for the meaning of radicalization process as 'the development of a belief in opinions, views and ideas that might well result in a person committing acts of terror'. Saadat [3] on her own also further explained radicalization as a process that has several factors including cognitive, cultural, social, affective, biological and historical factors.

Understanding radicalization is crucial for several reasons e.g. its presence which appears universal and exceed ideologies and borders, thus an interdisciplinary approach is needed. By interdisciplinary here means the component of social, psychological and biological should be integrated [3]. As mentioned earlier, Decety \& Workman [2] also proposed the importance of multiple layers perspective and interdisciplinary analyses to understand radicalization. By multiple layers and interdisciplinary here mean the method to analyze the precedents of radicalization should be done from several field e.g. political science, neuroscience, evolutionary theory, personality and social psychology.

Exploring the root causes for radicalization and terrorism, previous researchers Victoroff [4] and Roy [7] have summed up that ethnic background, religious affiliation, poverty, socioeconomic status, education, and relative deprivation are not the primary causes, although those aspects contributed in some process of radicalization. Moving to the social neuroscience role as a promising approach representing bottom-up perspective, several scientists; Cacioppo \& Bemston, Cacioppo \& Visser in Decety \& Workman [2] provided comprehensive explanation of social neuroscience scoop. They stated social neuroscience is an interdisciplinary field that examines the social structure, biological mechanism of behavior and the reciprocal relation between the biological and social levels of organization.

In brain-based level and biological perspective, many neuroscientists concluded that individual dispositions role in the radicalization process can be explained empirically through several longitudinal studies which were supported by neuroimaging data. The individual dispositions here include genetic predictors, cognitive flexibility, justice sensitivity, and cognitive closure. When individual dispositions meet stressors from surroundings and situational factors, violence can unquestionably be reinforced and occurs [3].

Moreover, previous study also provided clear evidence that biological factors may bolster the propensity individual has to perform aggressive behaviors. In this stage, early life stress e.g. maternal deprivation, maltreatment, and peer rearing were also mentioned having long-term drawbacks for the neurotransmitters development which correlated with aggressive behavior [3]. Discussing more specifically, justice sensitivity is a character trait that expresses how individual interpret the significance of justice issues in his/her daily basis. It also can be crucial indicator for individual's emotion and behavior related to justice [8]. In brain system level, several regions and functions are correlated with justice sensitivity, e.g. the dorsolateral and dorsomedial prefrontal cortex (dlPFC, dmPFC), posterior superior and temporal sulcus (pSTS). Those regions are linked with the mechanism of justice sensitivity when individuals assess others behavior in moral perspective [9].

Another study also supported the reciprocal relation between environmental factors and individual dispositions. When individual from minority group possess perceived injustice as a result of their justice sensitivity assessment because of several environmental factors such as a victimhood trait and getting perceived unfair treatment from surrounding, it will stimulate violent behavior [10]. In radicalization context, restoring justice was executed by minority groups because their justice sensitivity affects the moral judgment, thus they tend to see violence and aggressive behavior as acceptable tool to restore the justice itself [3].

Victoroff and colleagues [11] also supported the conclusion through their study. They described if individuals from the minority groups who live under suppressive environment that downsize their human rights, their justice sensitivity will produce perceived injustice in their mind which will provoke anger and motivation to reconstruct justice through violence and aggression. It can be concluded when individuals felt they were treated unlawfully they mostly will perform an act of violence to reach their version of justice restoration.

In their longitudinal studies where subjects asked to assess scenarios portraying interpersonal assistance or harm as morally good or bad, Decety \& Yoder, [12]; Yoder \& Decety[9]; Decety \& Workman [2] summed up justice sensitivity has been linked with brain activation in several regions which execute higher-order computational functions, e.g. goal understanding and mental state evaluation. In this process, individual justice sensitivity forecast neural response in posterior superior temporal sulcus (pSTS), dorsomedial prefrontal cortex (dmPFC), dorsolateral prefrontal cortex (dlPFC). Accordingly, certain individuals can be called highly sensitive to injustice. And in this category, the sensitivity to injustice are basically triggered by justice principles, not by personal distress or emotional contagion [13].

In different perspective yet still related to justice sensitivity, Baron-Cohen also [14] highlighted the importance of assessment for empathy level to understand the factors behind cruelty and evil behaviors. Using this approach, he concluded certain neural structures and its deficit function are the antecedent behind the cruel and evil behavior including harming others in certain level and form e.g. hurting physically, harming, and killing. Another study by Cheetham [14] summed up that functional neuroimaging data showed empathy as an extra disposition interfering obedience to authority. This conclusion refers to Milgram experiments where participants underwent scanning while viewing virtual reality about avatars who experienced pain. The scanning itself exposed the increase activation for several regions including amygdala and ventrolateral prefrontal cortex. 


\section{GENETIC PREDICTORS \& COGNITIVE INFLEXIBILITY}

As already mentioned in previous chapter, several genetic studies showed the link between genetic dispositions and the act of violence. Glen \& Raine [15] elaborated how metaanalyses for several gene-behavior related studies reached the conclusion that approximately $40-60 \%$ heritable effects accounted for aggressive and antisocial behavior. In this genetic dispositions context, it was argued as well that serotonin has an important role in terms of activating a harmavoidance bias [16].

Despite this gene-related theoretical framework, Krakowski [17] discussed the importance of viewing through broader perspective, not forgetting about reciprocal relation between the environment and genetic predispositions. He highlighted that in one hand genes influence social interactions and personality as well as psychological traits, on the other hand environmental and the nurturing factors also interfere the genes expression.

Moving on cognitive psychology viewpoint, Borum (in Saadat) [3] explained that terrorists see the world and its reality using a 'black or white' view. That absolute way of thinking, without even noticing about the possibility of 'grey area' between black or white, on the long way produced rigid and inflexible style in terms of understanding and expressing and articulate religion beliefs, morality issues and political beliefs. Decety \& Workman [2] further described the extremists have a very strict moral dualism which affects their view. Their thinking mechanism justify violence and aggression because there are just two conventional options for moral assessment; right and wrong without ambiguity. As a result, in order to preserve the weight of good and evil, they rationalized violence as one of the acts that can be executed.

Scott [18] described cognitive flexibility as mental capacity to shift between understanding about two different notion, and to understand about numerous concepts synchronously. Another explanation given by Cooper-Kahn \& Dietzel [19]. They stated cognitive flexibility as part of executive functions. There are two subdivision of cognitive flexibility; cognitive shifting and task switching. They perform depend on whether the change occurs consciously or unconsciously, respectively. Moreover, study by Zhong, et al [20] found that cognitive flexibility along together with openness are crucial although not the main character traits in term of habituating individual's religious beliefs. This conclusion support the explanation from Decety \& Workman [2] that individuals with high level of cognitive inflexibility and low level of ambiguity tolerant may become admirers for political, ideological or religious extremists.

Further explanation done by Victoroff [4]. He highlighted cognitive inflexibility as the factor behind the failure for anticipation of future consequences in terms of terrorist perspective. It can be argued there are diminished executive functions in this case, which these functions densely rely on pre frontal cortex. And when the cognitive inflexibility along together with ambiguity tolerance are excessive, they will stimulate terrorist being unable to acknowledge nuance, less adaptable and irrational in bargaining.
Kaplan, Gimbel \&Harris [21] described other brain regions correlated with cognitive inflexibility which are low activity in the orbitofrontal cortex (OFC) and the dorsolateral prefrontal cortex (dlPFC). Those two regions have crucial role on the process of overruling old information with new information and might be significant during the extreme beliefs development process. Moreover, decrease functioning in the dIPFC and OFC may provoke the changing process of individual's belief in replying a counterevidence.

Heavily associated with cognitive inflexibility, the concept of cognitive closure was proposed by many scientists. Webster \& Kruglanski [22] described cognitive closure as one's desire for definite and convinced answer on any given topic and the evasion of ambiguity. In this context, individuals who possess high level of cognitive closure hungry for structure and order in their surroundings, they will experience displeasure when confronted by ambiguity, desire secure or steady knowledge that can be relied upon. They also possess very low level of willingness to have their personal knowledge confronted by opposite or different opinions and evidence.

Another study by De Zavala et al [23] pointed out when individuals have a conservative world perspective with high cognitive closure, they will have bias when evaluating uncertainty within intergroup situations. As a result from it, individuals may accept and contribute to open conflicts, act of violence and aggression. More specifically, the desire for cognitive closure along with conservative view on politics are linked to out-group hostility in individuals who have a tendency to perceive an uncertain intergroup conflict which is not obviously stated as a conflict, as alarming and conflicting. Federico, Hunt \& Fisher [24] also described the demand for cognitive closure was connected to the status of perceived group. It also reinforces intergroup differentiation, which one of the main precursory of extremism.

\section{INTEGRATING MULTILAYERS PERSPECTIVES}

Many scientists agree on the need of comprehensive understanding about the precursory of extremism, terrorism and radicalism and it can be gained by incorporating evidence from multilayer disciplines e.g. neuroscience, neurobiology, sociology, psychology, economics, politics, and criminology. Burgeoning (in Decety \& Workman) [2] proposed the way to comprehend the antecedents of radicalization, violence in politics and extremism is by incorporating biological science evidence along together with other evidence from neuroscience, sociology and sociopolitical aspects. It can be argued the better conclusion cannot be produced simply from reassessing the related literature on individual dispositions, environmental situations, survey, and self-reports in single dimensional way, but rather incorporating them together.

Decety \& Workman [2] further concluded interpreting violent behavior and extremism should take into account of the brain organizational and molecular level, but not forgetting the determinants from environmental components. However, one thing should be understood clearly is all of those neurobiological antecedents for extremism, terrorism and radicalism that have been explained above, should not be misunderstood as the 
judgment for interpreting individuals who join terrorist organizations, become radicalized and execute extreme violence as psychiatric patients. Horgan (in Decety \& Workman) [2] pointed out individuals who are radicalized and perform violence and aggression as a part of terrorist organization are by definition ordinary people. They are fanatic and have different individual dispositions related to moral judgment, justice sensitivity, cognitive inflexibility and cognitive closure, but they are not psychotic, except the case for 'lone wolf' (perform an act of terror without having affiliation with any group or organization). Thus, ordinary people can possess extreme and radical views without becoming terrorists.

McCauley (in Decety \& Workman)[2] also stated ordinary people who develop strong emotional ties and values to extremism and radical narratives can become radicalized as well. Similar to this conclusion, study by Bronner (in Decety \& Workman) [2] also depicted that individuals who empathize with and join terrorist organizations are apparently rational and even educated. Decety \& Workman [2] further stated if ordinary and rational individuals are possible of possessing extreme and radical views and of becoming radicalized, the question is why those extremists comprise only a small part of society? At this point, interdisciplinary studies will deliver a comprehensive explanation for it, and that is the key reason why many metaanalyses studies recommend the multilayer and interdisciplinary research.

Saadat [3] explained the intersection between environmental factors and neurobiological factors occurs in a certain way. It is crucial to underline that all social behaviors are not material to biological and genetic factors, but those behaviors are material of obscure gene-culture interaction. Situational and surrounding factors can strengthen and suppress individual dispositions to take part in violence and aggression. In this phase, terrorism and radicalization studies need to combine biological and evolutionary views to explore the precedent of individuals violence. Decety \& Workman [2] deduced social neuroscience as a field that significantly gave contribution in terms of explaining intricate social behaviors and complicated brain-behavior relation e.g. risk taking behavior (Steinberg), social status and hierarchies (Koski,Xie \& Olson), and social support (Taylor; Uchino \& Smith; Birmingham \& Carlisle). The social neuroscience support transdisciplinary approach to integrate correlation between social processes and neural (cognitive) processes.

Woollett \& Maguire [25] stated neuroplasticity showed the brain malleability and the milieu can stimulate significant changes in brain structure and cognitive functions under certain circumstances. Schreiber et al [26] support the result by stating on the terrorism and radicalization context, the milieu effect on political behaviors may significantly decrease or increase the effect of genetic predispositions in terms of developing extreme reliance and performing violence and aggression.

We conclude based on the current evidence and explanation which provided in this review, that dynamic theoretical perspective with interdisciplinary approach (where social and biological field can be cooperated together) is in favor to unfold the underlying mechanism of radicalization. In the current literature review, minor limitations were discovered e.g. not all studies were done using interdisciplinary approach, rather those studies were executed in single dimensional way, thus the result should be integrated and analyzed later with other studies' results from different fields to get the sense of interdisciplinary. If future studies can be executed using interdisciplinary approach where each discipline work together since from the beginning of research phase, the clarity behind radicalization mechanism will be definitely accomplished.

\section{CONCLUSION}

The intricacies of relation between behavior and brain pose pivotal questions that cannot be responded by only one discipline alone. On the context of radicalization mechanism, brain-behavior perspective should be integrated with other disciplines in terms of analysis level and approach [2]. The goal of this literature review was to elaborated previous scientific studies focused on the theoretical explanation behind terrorist and extremist mind. The reviewed literature suggests interdisciplinary approach that contains social neuroscience to examine the mechanism behind radicalization through bottom up and top down analysis. Several studies described how individual dispositions e.g. justice sensitivity, gene predictors, cognitive inflexibility and cognitive closure correlated with the development of extreme violence behavior. Social neuroscience with its potential to explore the neural mechanism behind extremist and terrorist mind can be argued as the representation of advanced methodology and theory that produces a promising chance to explore old questions in contemporary ways and even discover new questions about cognition, behavior, and brain function [2]. When neuroscience data are engaged with other disciplines' analyses e.g. sociology, political science, criminology, economics and psychology, they will significantly enhance the understanding of human mind and behavior including for the mechanism of terrorist and violent-extremist mind [27]. To conclude, current research supports the development of neuroscience research with more advance technology, as discussed above; which unquestionably will advantage society.

\section{REFERENCES}

[1] A. Brodziak, "Contemporary Terrorism as a Challenge for Neuroscience," Journal of Neuroscience, Volume 1, Issue 1, 2016, PP 5-8 ISSN No. (Online) 2456-057X http://dx.doi.org/10.20431/ 2456-057X.0101003

[2] J. Decety \& C.I. Workman, "A multilevel social neuroscience perspective on radicalization and terrorism," Social Neuroscience, 13(5) - November 2017 https://doi.org/10.1080/17470919.2017.140 0462

[3] S. Saadat, "Towards a Neuroscience of Radicalization and Terrorism," Master Literature Thesis, 2018. M.Sc. Brain \& Cognitive Sciences: Behavioral Neuroscience University of Amsterdam

[4] J. Victoroff, "The mind of the terrorist : A review and critique of psychological approaches," Journal of 
Conflict Resolution, 49(1), 3-42.2005. https://doi.org/ 10.1177/0022002704272040

[5] J.T. Cacioppo \& J. Decety, "Challenges and opportunities in social neuroscience," Annuals of the New York Academy of Sciences, 1224(1), 162-173. 2011 https://doi.org/10.1111/j.1749-6632.2010.05858. x.Challenges

[6] J.V. Carson, G. Lafree \& L. Dugan, "Terrorist and nonterrorist criminal attacks by radical environmental and animal rights groups in the United States, 1970-2007. Terrorism and Political Violence, 24(2), 295-319. 2012. https://doi.org/10.1080/09546553.2011.639416

[7] O. Roy, "Jihad and death: the global appeal of Islamic State," London: C. Hurst \& Co, 2017

[8] J. Decety \& K.J. Yoder, "Empathy and motivation for justice: Cognitive empathy and concern, but not emotional empathy, predict sensitivity to injustice for others," Social Neuroscience, 11(1), 1- 14. 2015, https://doi.org/10.1080/17470919.2015.1029593

[9] K.J. Yoder \& J. Decety, "The Good, the Bad, and the Just: Justice Sensitivity Predicts Neural Response during Moral Evaluation of Actions Performed by Others," Journal of Neuroscience, 34(12), 4161-4166, 2014, https://doi.org/10.1523/JNEUROSCI.4648-13.20 14

[10] W. Koomen \& J. Van der Pligt, "The psychology of radicalization and terrorism," Routledge/Taylor \& Francis Group, 2016

[11] J. Victoroff, S. Quota, J. Adelman, B. Celinska, N. Stern, R. Wilcox \& R. Sapolsky, "Support for ReligioPolitical Aggression Among Teenaged Boys in Gaza : Part I", Psychological Findings, 36(February 2010), 219-231. https://doi.org/10.1002/ab.20348

[12] J. Decety \& K.J. Yoder, "The emerging social neuroscience of justice motivation," Trends in Cognitive Sciences, 21(1), 6-14. 2017 https://doi .org/10.1016/j.tics.2016.10.008

[13] J. Decety \& K.J. Yoder, "Empathy and motivation for justice: cognitive empathy and concern, but not emotional empathy, predict sensitivity to injustice for others," Social Neuroscience, 11(1), 1-14.2016, https://doi.org/10.1080/17470919.2015.1029593

[14] M. Cheetham, "Virtual Milgram: empathic concern or personal distress? Evidence from functional MRI and dispositional measures," Frontiers in Human Neuroscience, 3(October), 29.2009, https://doi .org/10 .3389/neuro.09.029.2009

[15] A.L. Glenn \& A. Rainne, "Neurocriminology: Implications for the punishment, prediction and prevention of criminal behaviour," Nature Reviews Neuroscience, 15(1), 54-63.2014, https://doi.org/10.1 038/nr n3640

[16] M. Crockett, L. Clark, M. Hauser \& T. Robbins, "Serotonin selectively influences moral judgment and behavior through effects on harm aversion. Proceedings of the National Academy of Sciences, 107(40), 1743317438. 2010, https://doi.org/10.1073/pnas.10093961 07

[17] M. Krakowski, "Violence and Serotonin: Influence of Impulse Control, Affect Regulation, and Social Functioning," Journal of Neuropsychiatry and Clinical Neurosciences, 15(3), 294-305. 2003 https://doi.org/ 10.1176/appi.neuropsych.15.3.294

[18] W.A. Scott, "Cognitive complexity and cognitive flexibility". Sociometry. 25 (4): 405-414. December 1962 doi:10.2307/2785779. JSTOR 2785779

[19] J. Cooper-Kahn \& L.C. Dietzel, "'What is executive functioning?". ldonline.org. National Center for Learning Disabilities and WETA-TV. Archived from the original on September 20, 2014

[20] W. Zhong, I. Cristofori, J. Bulbulia, F. Krueger \& J. Grafman, "Biological and cognitive underpinnings of religious fundamentalism," Neuropsychologia, 100(No vember 2016), 18-25. https://doi.org/10.1016/j.neuro psychologia.2017.04.009

[21] J.T. Kaplan, S.I. Gimbel \& S. Harris, "Neural correlates of maintaining one's political beliefs in the face of counterevidence," Scientific Reports, 6(December 2016), 1-11. https://doi.org/10.1038/srep39589

[22] D.M. Webster \& A.W. Kruglanski, "Individual differences in need for cognitive closure," Journal of Personality and Social Psychology, 67(6), 1049-1062 1994. https://doi.org/10.1037/0022-3514.67.6.1049

[23] A.G. De Zavala, A. Cislak \& E. Wesolowska, "Political Conservatism, Need for Cognitive Closure, and Intergroup Hostility," Political Psychology, 31(4), 521541. 2010. https://doi.org/10.1111/j. 1467-9221.2010. 00767.x

[24] C.M. Federico, C.V. Hunt \& E.L. Fisher, "Uncertainty and Status-Based Asymmetries in the Distinction Between the "Good" Us and the "Bad" Them: Evidence That Group Status Strengthens the Relationship Between the Need for Cognitive Closure and Extremity in Intergroup Differentiation," Journal of Social Issues, 69(3), 473-494. 2013. https://doi.org/10.1111/josi.120 25

[25] K. Woollett \& F.A. Maguire, "Acquiring "the knowledge" of London's layout drives structural brain changes," Current Biology, 21(24), 2109-2114. 2011. https://doi.org/10.1016/j.cub.2011.11.018

[26] D. Schreiber, G. Fonzo, A.N. Simmons, C.T. Dawes, T. Flagan, J.H. Fowler \& M.P. Paulus, "Red Brain, Blue Brain: Evaluative Processes Differ in Democrats and Republicans. PLoS ONE, 8(2), 9-14. 2013 https://doi. org/10.1371/journal.pone.0052970

[27] J. Decety \& J. Cacciopo, "Perspectives on Psychological Science," Frontiers in human neuroscience: the golden triangle and beyond. 5(6), 767-771.2010, https://doi.org/10.1177/1745691610388 780 